\title{
PENERAPAN METODE WAHDAH SEBAGAI UPAYA MENINGKATKAN TAHFIDZUL QURAN SISWA
}

\author{
Arga Wulang Loh Sandi 1) \\ Arip Febrianto ${ }^{2}{ }^{*}$ \\ 1,2 Program Studi Pendidikan Guru Sekolah Dasar \\ Universitas PGRI Yogyakarta \\ *E-mail: Arip@upy.ac.id
}

\begin{abstract}
This study aims to determine the Implementation of the 8 Juz of Tahfidzul Quran at SDIT Salsabila 4 Jetis Bantul. This research is qualitative. The subjects of this study were the principal and the Tahfidz teachers. Data collection techniques were interviews, observation, and documentation. The data analysis technique used was descriptive qualitative. I was checking the validity of the data used technical triangulation and source triangulation. The results of the study showed that the implementation of the $8 \mathrm{Juz}$ of Tahfidzul Quran Method in SDIT Salsabila 4 Jetis could reach the target using the wahdah method. And the rules in memorizing the Quran, really implemented. From eighteen Tahfidzul Quran students, nine students meet the 8 Juz target.
\end{abstract}

Keywords: Wahdah Methods, Tahfidzul Quran, 8 Juz

\begin{abstract}
Abstrak
Penelitian ini bertujuan untuk mengetahui Tahfidzul Quran 8 Juz di SDIT Salsabila 4 Jetis Bantul. Penelitian ini merupakan penelitian kualitatif. Subjek penelitian ini adalah kepala sekolah, dan guru tahfidz. Teknik pengumpulan data yaitu wawancara, observasi, dan dokumentasi. Teknik analisis data yang digunakan adalah deskriptif kualitatif. Pemeriksaan keabsahan data menggunakan triangulasi teknik dan triangulasi sumber. Berdasarkan hasil penelitian menunjukkan bahwa implementasi Tahfidzul Quran 8 Juz di SDIT Salsabila 4 Jetis bisa mencapai target dengan menggunakan metode wahdah. Dari target 8 juz dengan jumlah siswa Tahfidzul Quran 18 anak, terdapat 9 siswa yang memenuhi target 8 Juz.
\end{abstract}

Kata kunci: Metode Wahdah, Tahfidzul Quran, 8 Juz

\section{PENDAHULUAN}

Pada era globalisasi saat ini, anak cenderung lebih jenuh dan minat belajar membaca Al -Qur'an menjadi berkurang dikarenakan para pengajar menggunakan metode ceramah, metode tanya jawab, metode diskusi, metode pemberian tugas, dan metode Iq'ra dalam mempelajari ilmu tajwid (Febrianto et al., 2018). Dalam agama Islam pendidikan diambil dari Al-Quran dan Hadist yang mana Al-Quran merupakan kitab yang diturunkan kepada Nabi Muhammad sebagai petunjuk, pelajaran bagi umat islam. Al-Quran sebagai kitab suci umat islam dari masa ke masa pertama kali diturunkan sampai sekarang terjaga keaslian dan kemurniannya walaupun dalam sejarah banyak yang ingin menghancurkannya. Secara operasional 
sudah menjadi tugas dan kewajiban umat islam untuk selalu menjaga dan memeliharanya, salah satunya ialah dengan menghafalkannya.

Meningkatnya Krisis moralitas marak terjadi belakangan ini, seperti tawuran antar pelajar, seks bebas, kasus video yang kurang baik, penggunaan narkotika, dan berbagai macam kasus serupa salah satunya dikarenakan dunia pendidikan masih menitikberatkan dalam hal kognitif dan kurang memerhatikan dari aspek akhlak dan budi pekerti siswa (Rukhayati \& Muflihin, 2019).

Zaman modern sekarang ini masih sedikit umat islam yang memiliki kesadaran untuk menghafalkan Al-Quran. Menurut Muthi dan Usmi (Fauziyyah \& Karyani, 2017) mengemukakan bahwa menghafalkan Al-Quran memiliki manfaat hati tenteram, jiwa tenang, tidak merasa gelisah, takut dan khawatir sehingga menjadikan seseorang memiliki fokus atau konsentrasi yang tinggi. Abdul Aziz A.R (Abdul Aziz A.R, n.d.) mengemukakan bahwa Tahfidzul Quran (menghafal) adalah upaya mengakrabkan orang yang beriman dengan kitab sucinya sehingga tidak buta dengan isi yang ada di dalamnya. Oleh karena itu diperlukan metode yang sistematis untuk menunjang kesuksesan mereka dalam menghafal Al-Quran.

Achmad Rifai (Rifai, 2018) mengemukakan bahwa Pendidikan di sekolah pada hakekatnya merupakan suatu upaya mewariskan nilai, yang akan menjadi penolong dan penentu umat manusia dalam menjalani kehidupan, dan sekaligus untuk memperbaiki nasib dan peradaban manusia. Sekolah Dasar Islam Terpadu (SDIT) Salsabila Jetis yaitu Lembaga pendidikan dasar yang menyelenggarakan program pendidikan enam tahun berdasarkan kurikulum nasional yang diperkaya dengan kurikulum Islami secara terpadu (Khotimah, 2016). SDIT hadir dengan konsep sekolah karakter. Pembelajaran sedemikian rupa agar anak belajar dengan suasana ceria dan tidak membosankan.

Beberapa program unggulan ditawarkan di sekolah ini, seperti Tahfidzul Quran dengan target kelas tahfidz 10 juz dan regular 3 juz, Bahasa Internasional, ESQ for kids, program IPTEK, dan komputer (Badiah, 2016). Siswa juga dilatih terampil dan berjiwa entrepreneurship melalui pelatihan life skill. Sekolah ini menerapkan system Full Day School yang bercita-cita mewujudkan generasi yang cakap, cendikia, dan memiliki akhlaq mulia. Adapun caranya yaitu menanamkan nilai-nilai agama sejak dini, membiasakan anak berperilaku islami dalam kehidupan sehari-hari (Jaelani, 2019). 
SDIT Salsabila 4 Jetis sangat memperhatikan dalam hal perkembangan anak didiknya. Kemudian Peneliti tertarik untuk melakukan penelitian tentang Implementasi Metode Tahfidzul Quran 8 Juz di SDIT Salsabila 4 Jetis Bantul. Tahfidzul Quran ini menjadi salah satu program unggulan SDIT Salsabila 4 Jetis Bantul. Pembelajaran yang dilakukan di SDIT sangat menarik, tidak monoton dan hampir semua mata pelajaran dilaksanakan dengan senyaman mungkin agar anak-anak menjadi lebih giat lagi dan menyenangkan bagi mereka. Dalam pelaksanaan Tahfidzul Quran guru tidak hanya membawa anak-anak di dalam kelas namun juga dilakukan di luar kelas seperti dibawah pohon dan di lapangan depan halaman sekolah (Febrianto et al., 2017).

Pengaruh terhadap siswa yang mengikuti Tahfidzul Quran yaitu anak-anak yang hafalannya tinggi memiliki konsentrasi yang tinggi. Tahfidzul Quran ini juga sebagai salah satu upaya untuk menjaga alquran. Melihat dari latar belakang masalah diatas, maka diperlukan penelitian tentang pembelajaran tahfidzul quran di SDIT Salsabila 4 jetis Bantul karena sekolah tersebut mempunyai kegiatan yang menonjol dalam kegiatan belajar-mengajar dibandingkan dengan sekolah-sekolah yang lain, terutama dalam proses pembelajaran Tahfidzul Quran. Di sekolah lain untuk tingkat sekolah dasar belum ada yang memiliki target lulus sekolah dasar hafal 8 Juz, namun di SDIT SALSABILA 4 ini sudah menerapkan target menghafal tersebut.

\section{METODE}

Penelitian ini merupakan penelitian kualitatif. Penelitian ini dilakukan di SDIT Salsabila 4 Jetis Bantul. Penelitian ini dimulai pada bulan April sampai Juni 2020. Subjek penelitian ini adalah kepala sekolah, dan guru tahfidz. Teknik pengumpulan data yaitu wawancara, observasi, dan dokumentasi. Teknik analisis data yang digunakan adalah deskriptif kualitatif. Pemeriksaan keabsahan data menggunakan triangulasi teknik dan triangulasi sumber.

\section{HASIL DAN PEMBAHASAN}

\section{Metode Tahfidzul Quran 8 Juz}

Penelitian ini dilakukan di SDIT salsabila 4 jetis terletak Dusun Gatak, Desa Sumberagung, Kecamatan Jetis, Kabupaten Bantul, Propinsi Daerah Istimewa Yogyakarta. Adapun Visi Misi “SDIT Salsabila 4 Jetis Bantul” antara lain: 
1. Visi SDIT Salsabila 4 Jetis Bantul

“Terwujudnya Generasi Emas Qurani Indonesia 2045 yang cakap, cendikia dan berakhlak mulia"

2. Misi SDIT Salsabila 4 Jetis Bantul

a. Melaksanakan pembelajarana berbasis Al Qur'an dan sunah Nabi dengan pendekatan pembelajaran aktif, kreatif, efektif, inovatif, dan menyenangkan.

b. Melaksanakan Pembiasaan akhlak mulia.

c. Melaksanakan pelatihan untuk menumbuhkan dasar-dasar kecakapan hidup.

d. Melaksanakan program pendampingan personal sesuai bakat, minat dan potensi anak.

e. Membangun budaya belajar mandiri dalam membaca, menulis, dan berkarya. Ulfah,dkk (Metode et al., 2019) TQA bertujuan untuk membimbing anak-anak agar dapat membaca, memahami Al-Qur'an, dan mengamalkannya di kehidupan sehari-hari (Keswara, 2017).

\begin{tabular}{|c|l|c|c|}
\hline No & \multicolumn{1}{|c|}{ Nama } & L/P & Keterangan \\
\hline 1 & Abdurrahman Khoirul Farihin & L & 8 Juz \\
\hline 2 & Ahmad Ma'ruf Arzacky Pratama & L & Belum \\
\hline 3 & Arin Arum Nisa & P & 8 Juz \\
\hline 4 & Aulia Nuur Zahra & P & Belum \\
\hline 5 & Muhammad Naufal Rocha & L & 8 Juz \\
\hline 6 & Charizal Hidayat & L & 8 Juz \\
\hline 7 & Syifa Aulia Arsanti & P & Belum \\
\hline 8 & Yasmin Arina Ulfa & P & Belum \\
\hline 9 & Amitha Estava Ayodia & P & Belum \\
\hline 10 & Faith Athallah Ar Razi & L & 8 Juz \\
\hline 11 & Muhammad Adnan & L & 8 Juz \\
\hline 12 & Azalea Aurum Qotrun Nada & P & 8 Juz \\
\hline 13 & Naori Al Maliki & L & Belum \\
\hline 14 & Surya Shidiq Al-Ghifari & L & Belum \\
\hline 15 & Tifani Gangga Dewi & P & Belum \\
\hline 16 & Najwa Salsabila A & 8 Juz \\
\hline 17 & Rifky Adi Ilyasa & Belum \\
\hline
\end{tabular}




\begin{tabular}{|l|l|c|c|}
\hline 18 & Zulfa Nadia Hauraa Abidah P & P & $8 \mathrm{Juz}$ \\
\hline
\end{tabular}

Berdasarkan analisis interaktif, hasil observasi, dan wawancara yang dilakukan dapat disimpulkan bahwa penerapan metode wahdah pada Tahfidzul Quran 8 Juz telah dilakukan dengan baik, dan metode ini lebih sering digunakan oleh guru tahfidz maupun dari pihak sekolah dalam melaksanakan program Tahfidzul Quran 8 juz. Sehingga secara sederhana metode wahdah adalah metode untuk menghafalkan alquran dengan satu persatu secara berulang-ulang hingga benar-benar hafal, kemudian lanjut keayat-ayat berikutnya dengan cara yang sama, metode itu teruji bisa memenuhi target 8 juz, dari 18 anak siswa-siswi Tahfidzul Quran terdapat 9 anak yang memenuhi target.

\section{Menerapkan Metode Wahdah}

Adapun metode-metode tersebut yang perlu dilakukan, menurut Ahsin W. AlHafidz (Ahsin W. Al hafidz, n.d.) ialah: Metode Wahdah, yaitu menghafal satu persatu terhadap ayat-ayat yang hendak dihafalkan. Sehingga secara sederhana metode wahdah adalah metode untuk menghafalkan alquran dengan satu persatu secara berulang-ulang hingga benar-benar hafal, kemudian lanjut keayat-ayat berikutnya dengan cara yang sama. Implementasi yang sudah dilaksanakan di SDIT Salsabila 4 Jetis Bantul mencakup beberapa hal yang harus dipenuhi, faktor pendukung, usia yang ideal, manajemen waktu, tempat yang ideal, fasilitas, tahapan kerja dalam memori, dan kaidah-kaidah dalam menghafal alquran.

\section{SIMPULAN DAN SARAN}

\section{Simpulan}

Berdasarkan hasil penelitian dan pembahasan yang telah dilakukan, maka peniliti dapat menarik kesimpulan berdasarkan implementasi Tahfidzul Quran 8 juz sebagai yang dilakukan dalam memenuhi target 8 juz yaitu dengan menggunakan metode wahdah, dari target yang ditentukan 8 juz terdapat beberapa anak yang bisa memenuhi targetnya. Bisa dikatakan 50\% berhasil memenuhi target 8 Juz. Data yang didapatkan peneliti di kelas 6 berjumlah 18 Anak Siswa-Siswi Tahfidzul Quran. Dari 18 anak tersebut terdapat 9 anak yang bisa menghafalkan dengan target menghafal 8 Juz. 


\section{Saran}

Metode yang diterapkan SDIT Salsabila 4 Jetis sudah baik, sebab dari metode wahdah sudah dikembangkan menjadi metode kreatif, untuk kelanjutannya supaya ditingkatkan. Guru harus lebih dalam menyiapkan dan menyediakan pembelajaran Tahfidzul Quran yang inovatif pada anak-anak agar semakin banyak siswa yang bisa memenuhi target hafalannya. Hasil Penelitian ini dapat dijadikan bahan pertimbangan untuk dapat menggunakan metode ini untuk diterapkan pada sekolah lain.

\section{DAFTAR PUSTAKA}

Badiah, Z. (2016). Peranan Orang Tua dalam Mengembangkan Kecerdasan Emosional dan Spiritual (ESQ) Anak dalam Perspektif Islam. MUDARRISA: Jurnal Kajian Pendidikan Islam. https://doi.org/10.18326/mdr.v8i2.229-254

Fauziyyah, M., \& Karyani, U. (2017). Kesejahteraan Siswa: Studi Komparatif Siswa Berdasar Keikutsertaan Kegiatan Tahfidz. Indigenous: Jurnal Ilmiah Psikologi. https://doi.org/10.23917/indigenous.v2i2.4980

Febrianto, A., Informatika, J. T., \& Reality, A. (2018). View of PENGGUNAAN TEKNOLOGI AUGMENTED REALITY DALAM MEMPELAJARI ILMU TAJWID USE OF AUGMENTED REALITY TECHNOLOGY IN STUDYING TAJWID SCIENCE. 7(1), 8390.

Febrianto, A., Studi, P., \& Informatika, T. (2017). Program Aplikasi Scratch pada Mata Pelajaran Agama Islam Bagi. 17-20.

Jaelani, A. Q. (2019). Strategi Meningkatkan Kecerdasan Emosional dan Spiritual Siswa. KOMUNIKA: Jurnal Dakwah Dan Komunikasi. https://doi.org/10.24090/komunika.v13i1.2056

Metode, I., Dalam, I., Membaca, P., \& An, Q. U. R. (2019). PENDAHULUAN ajaran Islam ( Farkhan , 2019: 2), hikmah ( Durriyah, 2016:1), sebagai pedoman dan hidup bagi manusia (Hermawan , 2018 : 27-35). Bahkan, membacanya dihitung ibadah dan memperoleh pahala dari Allah swt. (Siregar , 2018: 1-28) Untuk. 2(2), 5969.

Rifai, A. (2018). STRATEGI KEPALA SEKOLAH DALAM IMPLEMENTASI PENDIDIKAN NILAI DI SEKOLAH. Ta'dibuna: Jurnal Pendidikan Agama Islam, 1(1), 1-10. http://dx.doi.org/10.30659/jpai.1.1.1-10

Rukhayati, E., \& Muflihin, A. (2019). PENGARUH PENERAPAN KURIKULUM KHAS TERHADAP PEMBENTUKAN KARAKTER SISWA DI SDIT PERMATA BUNDA. TA'DIBUNA: Jurnal Pendidikan Agama Islam, 2(2), 39-46. 